\title{
SPATIAL DISTRIBUTION AND TEMPORAL TREND OF PAN EVAPORATION IN THE THREE GORGES RESERVOIR AREA AND ITS SURROUNDINGS DURING 1952-2013
}

\author{
HE, H. P. ${ }^{1,2}-$ WU, S. J. ${ }^{1}-$ MA, M. H. ${ }^{1}-$ WEN, Z. F. ${ }^{1}-$ LV, M. Q. ${ }^{1}-$ CHEN, J. L. ${ }^{1 *}$ \\ ${ }^{1}$ Chongqing Institute of Green and Intelligent Technology, Chines Academy of Sciences \\ Chongqing 400714, China \\ (tel: +86-023-65935555; fax: +86-023-65935000) \\ ${ }^{2}$ University of Chines Academy of Sciences \\ Beijing 100049, China \\ (tel: +86-010-88256153; fax:+86-010-88256415) \\ *Corresponding author \\ e-mail: chenjilong@cigit.ac.cn \\ (tel :+86-023-65935912; fax: +86-023-65935000) \\ (Received 13 $3^{\text {th }}$ Jan 2017; accepted $4^{\text {th }}$ Apr 2017)
}

\begin{abstract}
Under climate warming and impoundment conditions of the Three Gorges Reservoir (TGR), spatial distribution and temporal trend of pan evaporation in the Three Gorges Reservoir Area (TGRA) and its surroundings offer valuable information about regional hydrology and ecosystem succession. In this study, pan evaporation measured by a pan of $20 \mathrm{~cm}$ diameter at 27 meteorological stations during 1952-2013 in the TGRA and its surroundings were calculated, compared and analyzed. Their spatial distribution and temporal trend were examined and the causes for the variations are discussed. The results show that: (1) The average annual pan evaporation in the TGRA and its surroundings is $1208.03 \mathrm{~mm}$, and it appears an east-west downward gradient. (2) Examined by Mann-Kendall (MK) test, pan evaporation significantly declined at the rate of $-40.8 \mathrm{~mm} /$ decade during 1952-2013. It shows upward trend in 1960s, 1970s, but downward trend in 1980s and 2000s. (3) The decreasing of pan evaporation is the results of comprehensive influences of air temperature (TEM), wind speed (WIN), sunshine duration (SSD) and relative humidity (RHU). Among them, SSD is the largest contributor.
\end{abstract}

Keywords: climate change; Mann-Kendall test; linear regression; sunshine duration; evaporation paradox

\section{Introduction}

Evaporation is a key component of the global water and energy cycle (Schlesinger and Jasechko, 2014). Since over $71 \%$ of the earth's surface area is covered by water, evaporation is the major portion of water loss (Yang et al., 2014). It is also one of the most considered meteorological factors in agricultural and ecological decision making (Trenberth and Asrar, 2014).

In general, there are two ways to estimate the evaporation: one is to calculate it according to metrological parameters, such as solar radiation, temperature, humidity and wind speed. Another is to measure it directly in the field (Rowshon et al., 2014). Due to the cost of measuring numerous parameters and difficulty in maintenance and calibration, measuring evaporating rate from a pan filled with water is easily obtained, and thus, 
widely used (Xie et al., 2015). In the absence of rain, the amount of water evaporating during a certain period closely corresponds with the decrease in water depth in that period. It is a simple integrative measurement of complex meteorological interactions. Pan evaporation has been recognized as an integrative indicator for hydrological response to climate change (Brutsaert, 2016). Although it cannot fully present the actual evaporation, it has been found to have close physical contract with the actual evaporation, and is often used to estimate potential evaporation and reference evapotranspiration, as well as to forecast agricultural production (Valipour, 2014).

Decreases in pan evaporation over the past half century have been reported in many regions around the world associated with climate change (Fu et al., 2009). In Northern Hemisphere, such as the United States of America (1948-1998) (Lawrimore and Peterson, 2000; Hobbins et al., 2004), India (1940-1990) (Chattopadhyay and Hulme, 1997), Kingdom of Thailand (1982-2000) (Tebakari et al., 2005), Turkey (1979-2001) (Ozdogan and Salvucci, 2004), Italy (1878-1999) (Moonen et al., 2002) and the former Soviet Union (1951-1990) (Peterson et al., 1995), the pan evaporation showed statistical significant downward trend. The similar phenomena also was observed in the countries of southern hemisphere, such as Australia (1975-2004) (Roderick and Farquhar, 2004, Rayner, 2007), New Zealand (1970-2000) (Roderick and Farquhar, 2005) and South Africa (1974-2005) (Hoffman et al., 2011). However, a slight increase of pan evaporation was still found in some small regions. According to Tabari's research, 10 of the 12 stations showed increasing trends in the West of Iran during 1982-2003 (Tabari and Marofi, 2010). Vicente and Rodrigues documented that all stations except one presented an increasing trend in northeast Brazil, 1964-1993 (da Silva, 2004). In general, the pan evaporation appears a significant declined trend at global scale.

The decline in pan evaporation indicates the decline of potential and actual evaporation (Zuo et al., 2016). It is far from the expected evaporation increasing from global warming, which is called evaporation paradox (Modak et al., 2015). It is reported that temperature of the Earth surface increased by $0.85{ }^{\circ} \mathrm{C}$ over the past 130 years (IPCC, 2013). One of the expected consequences of global warming is that the air near the Earth surface become drier, resulting in an increase of evaporation (Liu et al., 2011a). However, as showed by previous studies, observations are opposite to what expected, which has given rise to further studies on pan evaporation trends in exploring reasons behind the big difference. One explanation is that the decrease in pan evaporation is consistent with decreasing solar irradiance due to increase in cloud coverage and aerosol concentration (Ji et al., 2012; Jones et al., 2012). The others hold the view that the rising temperature will increase the actual evaporation, then raise the air humidity, thus reduce evaporation from the pan (Liu et al., 2011b).So far, these existing explanations remain controversial (Liu et al., 2011a). It seems that the different study areas and approaches could lead to different conclusions. Additional data and analyses will be needed to explain the mechanisms behind the widely observed decline in pan evaporation for understanding the influence of climate change on the global hydro-cycle.

China is located at the eastern part of the Eurasian Continent and of intricate topography and diverse climate types (Ge et al., 2015). Therefore, the study of pan 
evaporation trends in China is of high importance to reveal the characteristics and its attribution on specific terrain and climate conditions. The Three Gorges Reservoir, known as the largest newly built reservoir, stretches $660 \mathrm{~km}$ upstream with average 1.1 $\mathrm{km}$ wide, and encompasses a total area of $1084 \mathrm{~km}^{2}$ at the maximum storage water level (Tang et al., 2016). The expected consequence is that the expanded water surface area will increase the air humidity, which could reduce the pan evaporation (Strachan et al., 2016). Although the decreasing trend was showed in the most part of China, such as Yellow River Basin (Ji et al., 2012), Tibetan Plateau (Liu et al., 2011b), even Yangtze River (Wang et al., 2011) as a whole, reducing solar radiation is the main causes. So, here comes two questions: 1 . what is the trend of pan evaporation in Three Gorges Reservoir Area (TGRA) and its surroundings, decreasing or increasing? and 2. what is the main influential factor of pan evaporation, solar irradiation or air humidity? To answer these questions, additional analysis focusing on TGRA is needed.

The objectives of this study are: (1) to present the spatial distribution of the pan evaporation in TGRA and its surroundings; (2) to investigate the trend of pan evaporation from 1952 to 2013 in this region; (3) to explore the possible causes of pan evaporating rate change.

\section{Materials and methods}

\section{Study area}

This study focuses on the TGRA and its surroundings (Fig. 1), located in the junction of the middle and upper reaches of the Yangtze River. Its water storage capacity reaches up to 39.3 billion $\mathrm{m}^{3}$, accounted for about $4 \%$ of the annual runoff of Yangtze River (Yang et al., 2006). The elevation increases and then decreases from west to east, ranging between 20 and $3000 \mathrm{~m}$. The western and eastern part of this area is dominated by rolling hills on the edge of Sichuan Basin and Middle-Lower Yangtze Plain, respectively (Wu et al., 2003). And the central part is dominated by Middle-Mountain District of Hubei, forming a series of canyons (Fu et al., 2010). Due to the prevailing of the Eastern Asian monsoon, the study area is in subtropical humid climate zone that is hot and humid in summer, but cool and dry in winter. Annual mean temperature is between 16.5 and $19{ }^{\circ} \mathrm{C}$, and annual precipitation is about $1100 \mathrm{~mm}, 80 \%$ of which is from April to October (Wu et al., 2004).

\section{Sites and data}

Stations span a range from $28^{\circ}$ to $32^{\circ} \mathrm{N}$ of latitude, $105^{\circ}$ to $112^{\circ} \mathrm{E}$ of longitude, and 31 to $1180 \mathrm{~m}$ of altitude. Table 1 shows the detailed information of the studied meteorological stations. For each station, daily meteorological records of mean air temperature (near surface), wind speed, sunshine duration, relative humidity and pan evaporation between 1952 and 2013 were acquired from Daily Data Set of Chinese Terrestrial Climate Data, provided by National Meteorological Information Centre of China (NMIC) of China Meteorological Administration (CMA). 


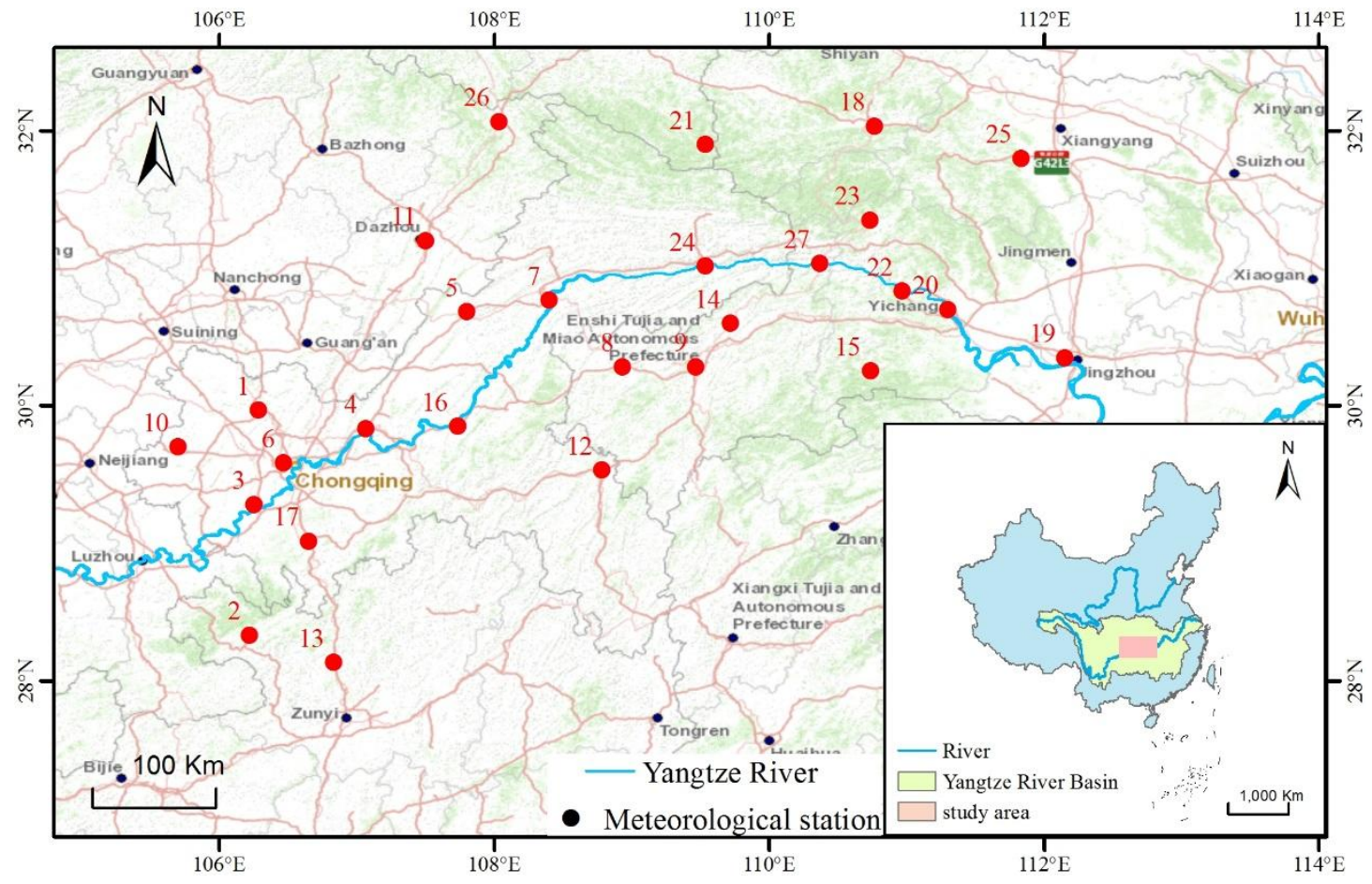

Figure 1. Location of the study area and 27 meteorological stations

To ensure the quality and consistency of the data used for this study, several steps are taken. For the data missing less than 3 days in one month, averaging daily data of the same month was used to estimate the missing observation of the days. For the data were missing more than 3 days in one month, the month data was excluded. The average month data of the excluded month in 1952-2013 were used to make interpolation for the month. The average of missing data in this study is less than $5 \%$ of all 27 stations.

Table1. General Information for 27 surveyed Meteorological Stations

\begin{tabular}{c|ccccc}
\hline Cite ID & Cite Name & $\begin{array}{c}\text { Altitude } \\
(\mathbf{m})\end{array}$ & $\begin{array}{c}\text { Longitude } \\
\left({ }^{\circ} \mathbf{E}\right)\end{array}$ & $\begin{array}{c}\text { Latitude } \\
\left({ }^{\circ} \mathbf{N}\right)\end{array}$ & $\begin{array}{c}\text { Annual mean } \\
\mathbf{E}_{\mathbf{p}}(\mathbf{m m})\end{array}$ \\
\hline 1 & Hechuan & 230.6 & 106.28 & 29.97 & 904.26 \\
2 & Xishui & 1180.2 & 106.22 & 28.33 & 998.35 \\
3 & JIangjin & 261.4 & 106.25 & 29.28 & 1060.13 \\
4 & Changshou & 377.6 & 107.07 & 29.83 & 1062.85 \\
5 & LIangping & 454.5 & 107.8 & 30.68 & 1068.62 \\
6 & Shapingba & 259.1 & 106.47 & 29.58 & 1074.32 \\
7 & Wanzhou & 186.7 & 108.4 & 30.77 & 1077.62 \\
8 & Lichuan & 1074.1 & 108.93 & 30.28 & 1083.39 \\
9 & Enshi & 457.1 & 109.47 & 30.28 & 1085.21 \\
10 & Dazu & 394.7 & 105.7 & 29.7 & 1087.54 \\
11 & Daxian & 344.9 & 107.5 & 31.2 & 1088.86 \\
\hline
\end{tabular}




\begin{tabular}{l|ccccc}
\hline 12 & Qianjiang & 607.3 & 108.78 & 29.53 & 1108.20 \\
13 & Tongzi & 972 & 106.83 & 28.13 & 1121.81 \\
14 & Jianshi & 609.2 & 109.72 & 30.6 & 1159.45 \\
15 & Wufeng & 619.9 & 110.67 & 30.2 & 1173.94 \\
16 & Fengdu & 290.5 & 107.73 & 29.85 & 1184.49 \\
17 & Qijiang & 254.8 & 106.65 & 29.02 & 1239.87 \\
18 & Fangxian & 426.9 & 110.77 & 32.03 & 1269.03 \\
19 & Jingzhou & 31.8 & 112.15 & 30.35 & 1288.89 \\
20 & Yichang & 133.1 & 111.3 & 30.7 & 1328.29 \\
21 & Zhenping & 995.8 & 109.53 & 31.9 & 1354.85 \\
22 & Zigui & 295.5 & 110.97 & 30.83 & 1366.21 \\
23 & Xingshan & 336.8 & 110.73 & 31.35 & 1402.45 \\
24 & Fengjie & 299.8 & 109.53 & 31.02 & 1422.23 \\
25 & Nanzhang & 151 & 111.83 & 31.8 & 1445.48 \\
26 & Wanyuan & 674 & 108.03 & 32.07 & 1515.58 \\
27 & Badong & 334 & 110.37 & 31.03 & 1644.82 \\
\hline
\end{tabular}

( $\mathrm{E}_{\mathrm{p}}$ : pan evaporation)

\section{Mann-Kendall non-parametric test}

The Mann-Kendall non-parametric analysis was used to test the significance of trends in hydro-meteorological time series (Croitoru et al., 2013). The equation below is often used to estimate whether a series has a significant trend or not:

$$
\mathrm{M}=\tau / \sigma_{\tau}
$$

in which:

$$
\begin{aligned}
& \tau=\frac{4 \mathrm{~S}}{\mathrm{~N}(2 \mathrm{~N}-1)}-1 \\
& \sigma_{\tau}^{2}=\frac{2(2 \mathrm{~N}+5)}{9 \mathrm{~N}(\mathrm{~N}-1)}
\end{aligned}
$$

where $\mathrm{S}$ is the number of the dual observed values in a series. $\mathrm{N}$ is the series length. For a fixed significance level $\alpha=0.05$ in the present paper, if a series has a significant trend, i.e. $|\mathrm{M}|>\mathrm{M}_{\mathrm{a} / 2}=1.96$; a positive indicate an ascending trend, and vice versa (Litchfield and Wilcoxon, 1955). 


\section{Linear regression}

Unitary linear regression was used to identify the trends of Ep in a time series, and calculate the climate change rate (Shenbin et al., 2006). The climate change tendency of the meteorological element is simulated by simple linear equation:

$$
\widehat{\mathrm{x}_{\mathrm{t}}}=\mathrm{a}_{0}+\mathrm{a}_{1} \mathrm{t}
$$

where $\widehat{x_{t}}$ is the simulated value of the meteorological element and $t$ is the time series (i.e. the year sequence); $a_{0}$ is constant; is the trend of $E_{p} \cdot a_{1}-10$ is climate change rate of the meteorological element per decade.

In addition, multivariable linear regression model was applied to analyze influence of other meteorological elements on Ep:

$$
z \hat{y}=\beta_{0}+\beta_{1} z x_{1}+\beta_{2} z x_{2}+\cdot+\beta_{i} z x_{1}
$$

where $\mathrm{z} \hat{y}$ stands for estimated value; $\mathrm{zx}_{1}, \mathrm{zx}_{2}, \cdots \mathrm{zx}_{\mathrm{n}}$ is the variables after standardization; $\beta_{0}, \beta_{1}, \beta_{2} \cdots \beta_{n}$ is the coefficient after standardization (Almazroui et al., 2014; Xia et al., 2015).

\section{Results and discussions}

\section{Spatial distribution of pan evaporation}

The spatial distribution of annual pan evaporation averaged over the past 62 years are plotted in Fig. 2. The average annual pan evaporation was $1208.03 \mathrm{~mm}$. It varied between $904.26 \mathrm{~mm}$ at Hechuan station and $1644.82 \mathrm{~mm}$ at Badong station, according to the calculation results based on the records of the 27 Meteorological Stations in our study area. The highest values were found in the east of the region and it decreased gradually to the west, contrary to flow direction of the Yangtze River. Among 27 stations, the average pan evaporation of the 14 stations located in the Northern bank is $1212.05 \mathrm{~mm}$, and $1203.70 \mathrm{~mm}$ in the Southern bank. The variation at the north-south direction was in insignificant level. The average annual pan evaporation inside the TGRA is $1357.81 \mathrm{~mm}$. But its surrounding area is $1176.08 \mathrm{~mm}$, which is much smaller than the inner TGRA. Table 2 shows some reasons. In the surroundings of the TGRA, lower air temperature and shorter sunshine duration generate less heat energy. Therefore, it provides insufficient thermal power for water molecule to escape from the molecular attraction. In addition, even though it has faster wind speed to transfer gas water molecules, the much more precipitation still lead to the higher relative humidity. Accordingly, the difference of saturation vapor pressure between the evaporation surfaces is smaller. They are the main reasons leading to the results found in this study. 


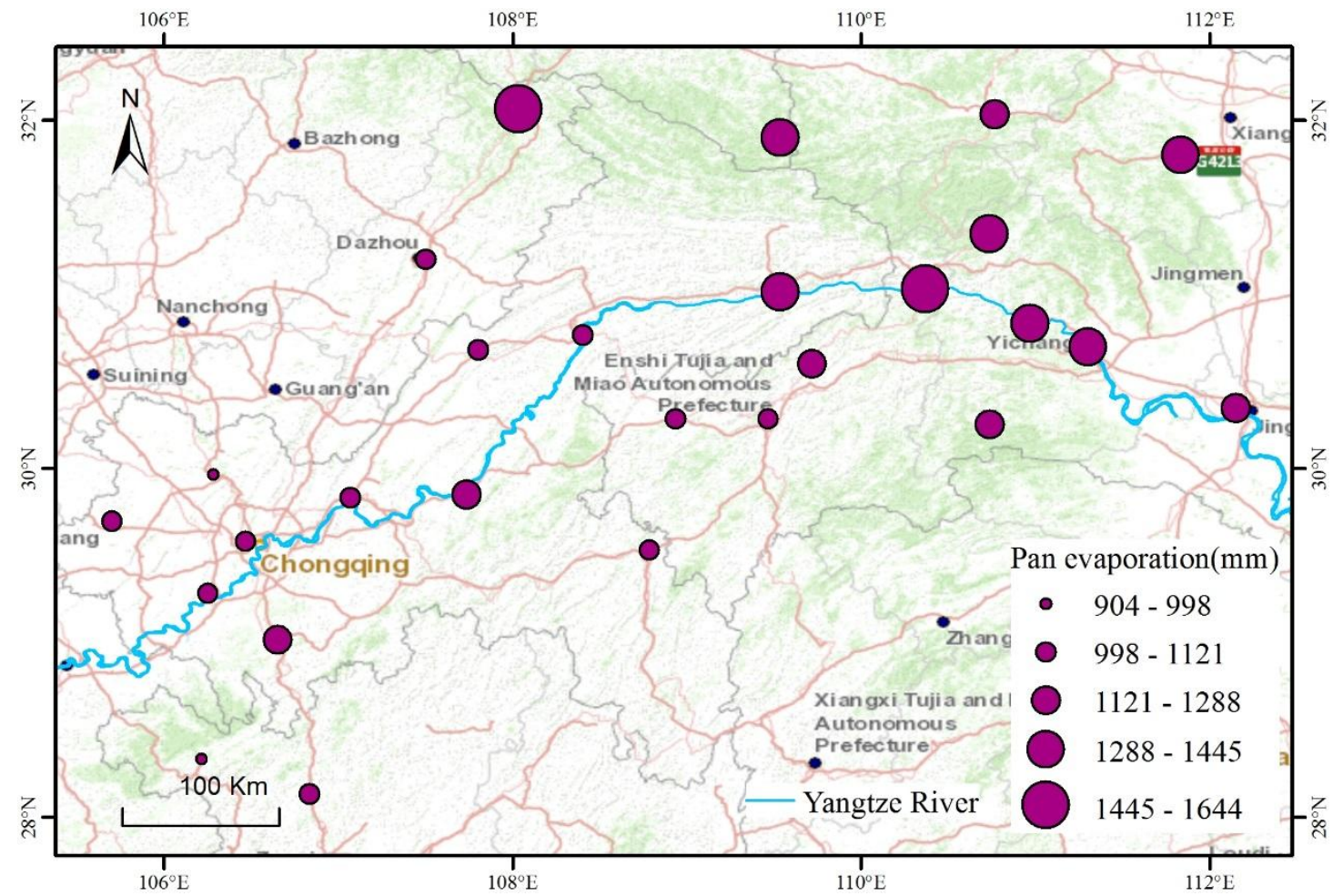

Figure 2. Spatial distribution of mean annual Ep in study area during 1952-2013

Table 2. Annual mean values of metrological elements in TGRA and its surroundings

\begin{tabular}{ccc}
\hline Metrological Element & TGRA & Surroundings \\
\hline Pan Evaporation $(\mathrm{mm})$ & 1262.34 & 1180.87 \\
Wind Speed $(\mathrm{m} / \mathrm{s})$ & 1.30 & 1.40 \\
Sunshine Duration $(\mathrm{h})$ & 1395.36 & 1354.70 \\
Air Temperature $\left({ }^{\circ} \mathrm{C}\right)$ & 17.72 & 15.64 \\
Relative Humidity $(\%)$ & 76.16 & 78.77 \\
Precipitation $(\mathrm{mm})$ & 1084.16 & 1139.16 \\
\hline
\end{tabular}

The spatial distribution of seasonal pan evaporation is shown in Fig. 3. Comparing to the results in Fig. 2, seasonal pan evaporation shows a roughly similar pattern of spatial distribution, indicating a significant east-west gradient in four seasons. The highest values of pan evaporation were found in the summer, but the lowest were found in the winter (Fig. 3), indicating a similar distribution of heat and rain. In summer, the pan evaporation accounted for $42.36 \%$ of the whole year. But in winter, the proportion is only $10.11 \%$. Spring and autumn cover the rest $47.53 \%$. 


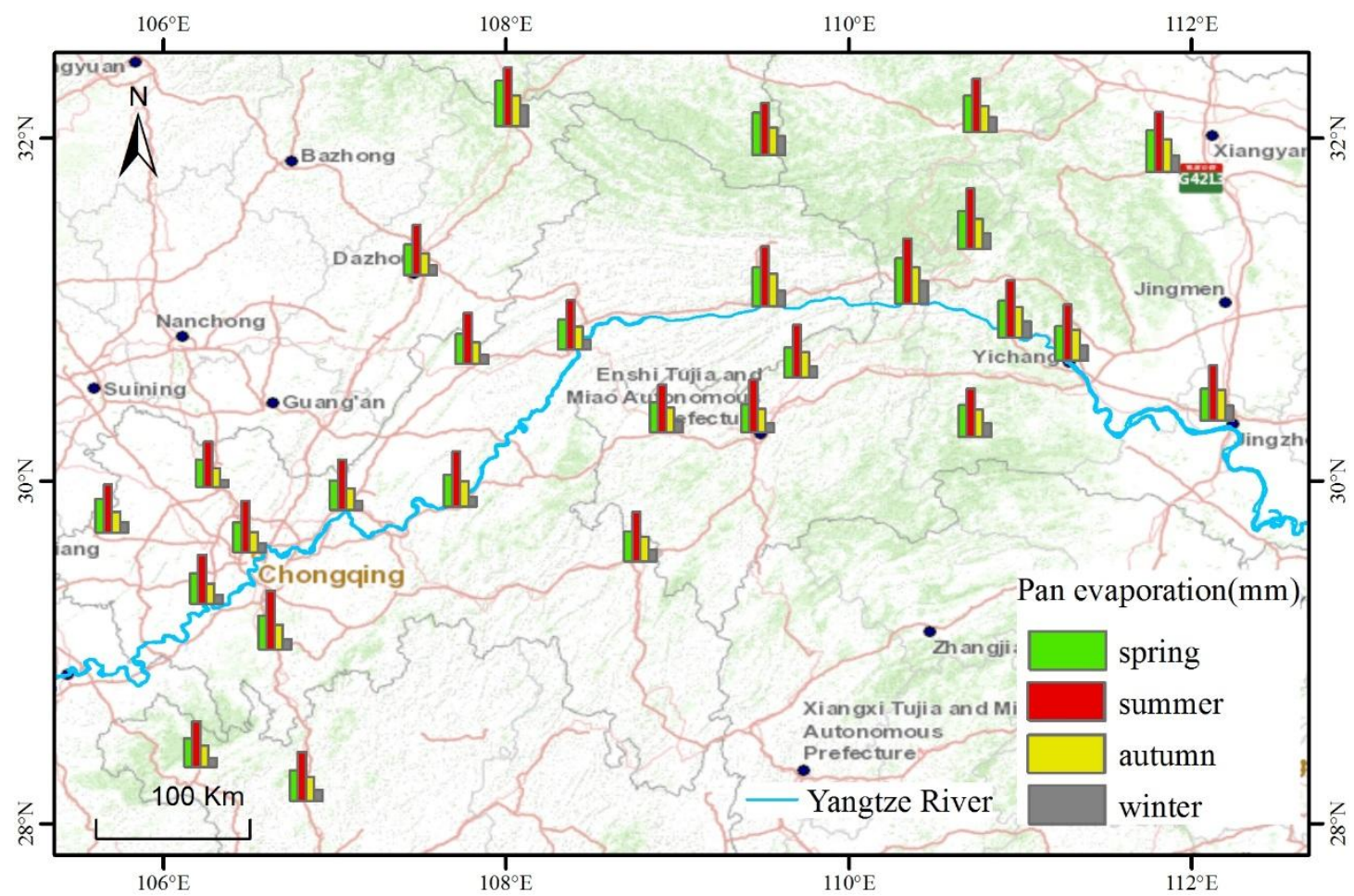

Figure 3. Spatial distribution of mean seasonal Ep in study area during 1952-2013

By using lines regression in analyzing the relationship between altitude, longitude, latitude and Ep (Fig. 4), results indicate that mean annual Ep exists increasing gradient with $58 \mathrm{~mm}$ per degree westward $(\mathrm{p}=0.072), 106 \mathrm{~mm}$ per degree northward $(\mathrm{p}=0.000)$, but there is no significant relationship between Ep and altitude $(\mathrm{p}=0.901)$. However, the climate factor may be the main factor affecting the spatial distribution of the pan evaporation. Fig. 5 shows the spatial distribution of the SSD, TEM, WIN and RHU respectively. Sunshine duration and wind speed spatially distribute in same trend as the pan evaporation, increasing from southwest to the northeast. But the air temperature and the relative humidity is in the opposite. The faster wind speed and the longer sunshine duration provide the water molecule for more heat energy and kinetic energy to get rid of the attractive forces between molecules. As a result, water phase transits from liquid state to gas state. Therefore, these places show a higher pan evaporation. But the places with higher temperature, unexpectedly shows a lower pan evaporation. This is consistent with the phenomenon of evaporation paradox. When the temperature goes up, the actual evaporation of the open water area will increase immediately in response. Then the relative humidity of the whole area goes up. Eventually it turns out to be a lower pan evaporation. Thus, the high temperature in the TGRA and its surroundings can result in the low pan evaporation spatially. 

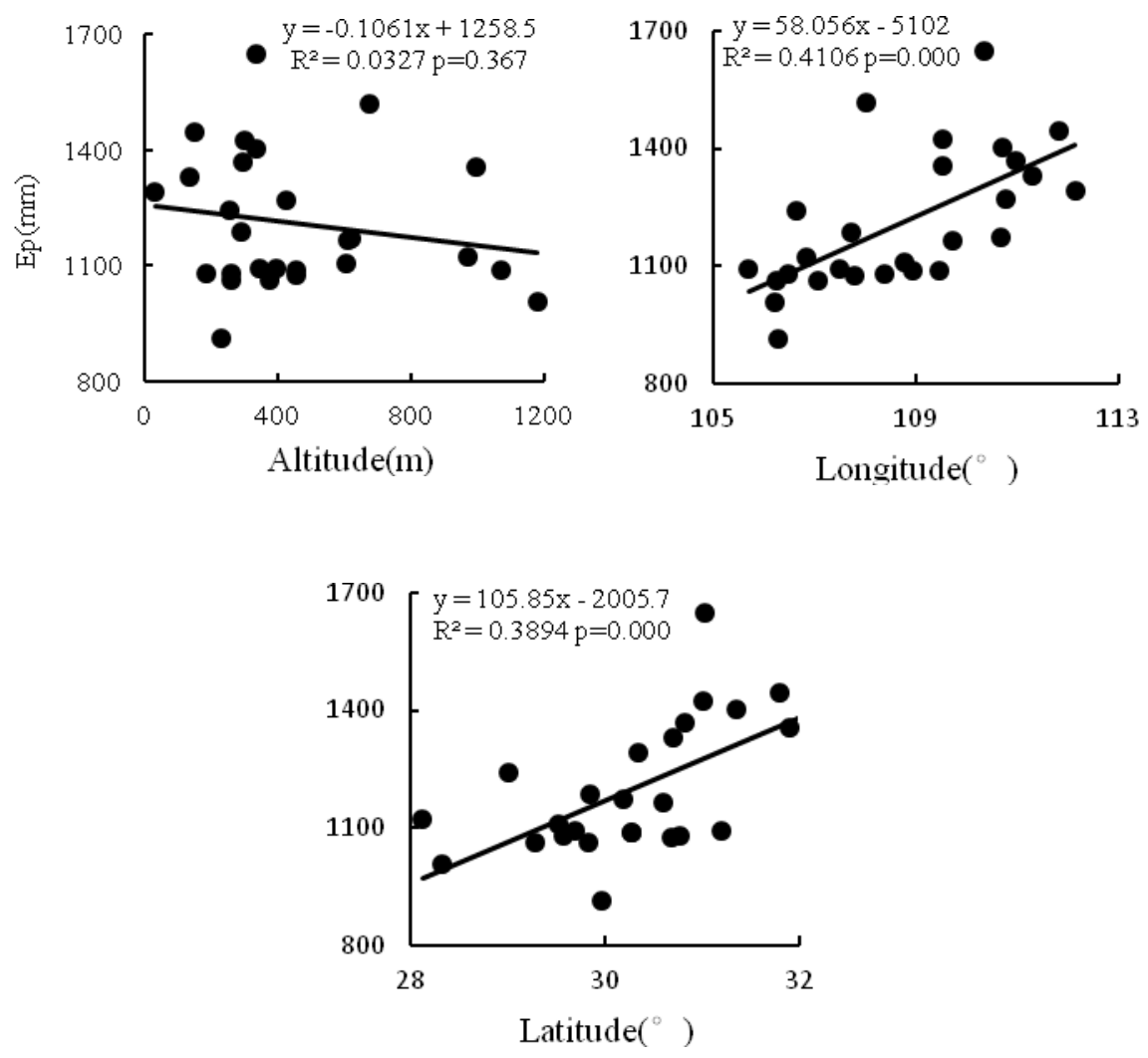

Figure 4. Relationship between altitude, longitude, latitude and mean annual pan evaporation

\section{Temporal trend of pan evaporation}

Ep decreased during 1952-2013 (Fig. 6) in study area. By Mann-Kendall test, this downward trend was at statistical significant level $(\mathrm{p}=0.000)$, in a satisfied agreement with the findings reported in several other districts in China, such as Yellow river basin, Haihe river basin, Songnen plain, Huang-Huai-Hai plain etc. However, in our study, the climate changing rate of the TGRA was about $-40.8 \mathrm{~mm} /$ decade, higher than the national average level, which is $-29.3 \mathrm{~mm} /$ decade stated by Binhui Liu (Liu et al., 2004).

Among 27 stations, 18 stations present negative trend in annual Ep which accounts for $70 \%$ of all the stations, and 9 stations show the positive trend, in which only 2 stations had the significant upward trend (Table 3).

Evaporating rate in about $45 \%$ of stations decreases from -60.0 to $-30.0 \mathrm{~mm} / \mathrm{dec}$ ade, $30 \%$ from -30.0 to $0 \mathrm{~mm} /$ decade, the rest $25 \%$ from 0 to $26.0 \mathrm{~mm} / \mathrm{decade}$. The highest magnitudes of the pan evaporation decreasing and increasing trends was obtained at Zigui and Enshi stations, counting $-59.3 \mathrm{~mm} /$ decade and $25.1 \mathrm{~mm} /$ decade respectively (Table 4). 

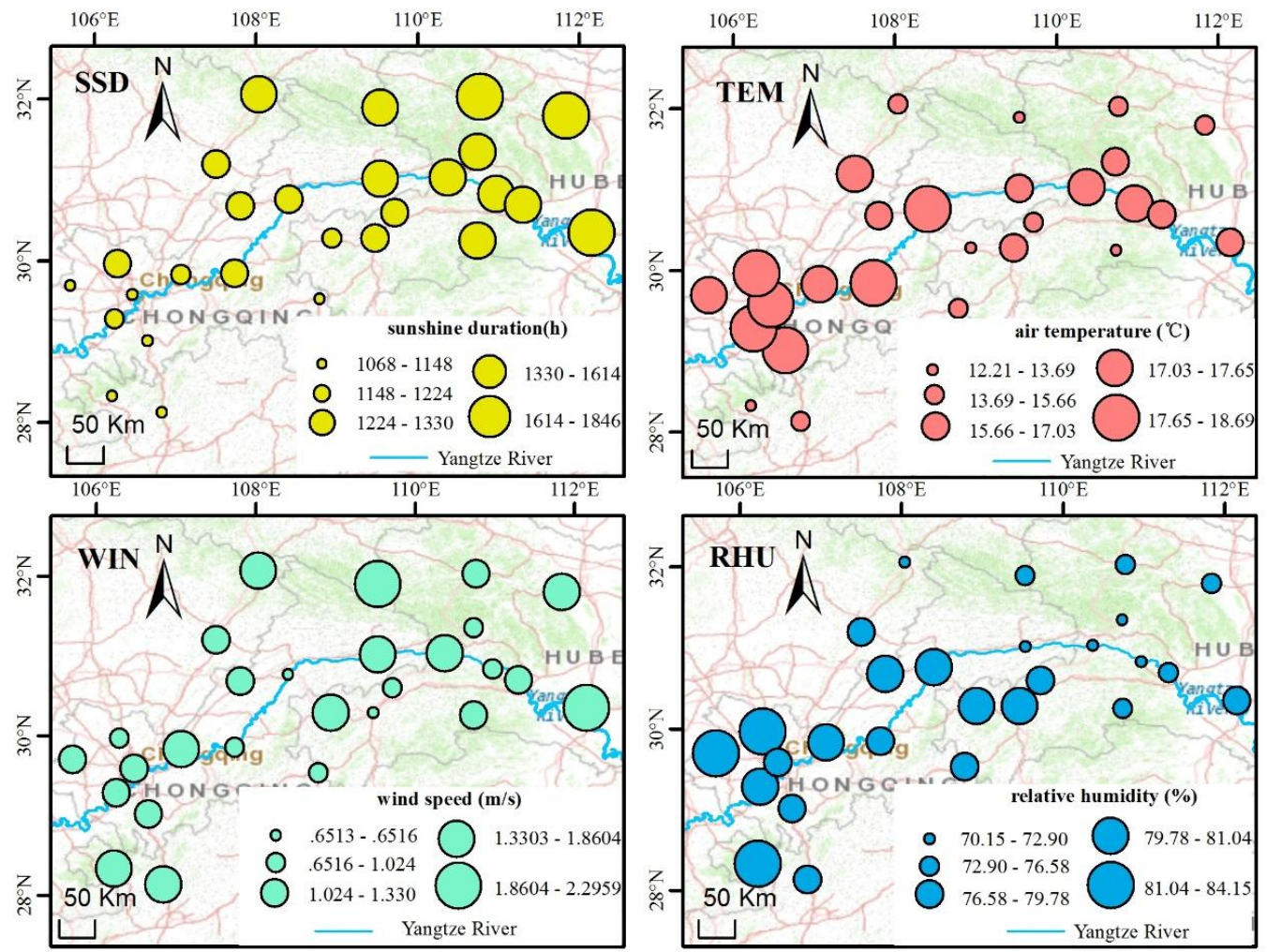

Figure 5. Spatial distribution of mean annual SSD, TEM, WIN, RHU in study area during 1952-2013

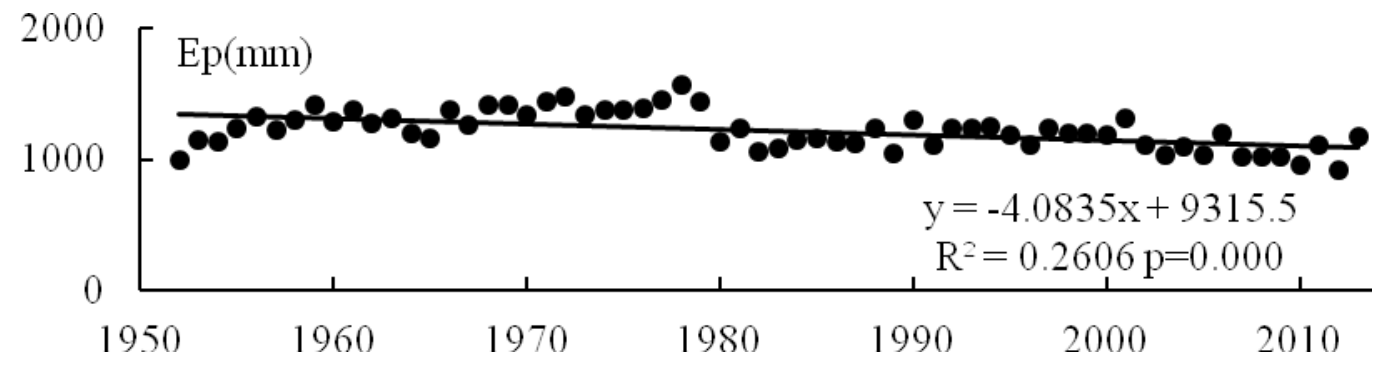

Figure 6. Mean annual pan evaporation trend by linear regression in study area during $1952-2013$

Table 3. Statistic results of Mann-Kendall test

\begin{tabular}{c|ccc}
\hline Trend & Total & $\begin{array}{c}\text { Significant } \\
\text { (at 0.05 confidence level) }\end{array}$ & $\begin{array}{c}\text { Non-significant } \\
\text { (at 0.05 confidence level) }\end{array}$ \\
\hline Decreasing & 17 & 8 & 9 \\
Increasing & 10 & 2 & 8 \\
\hline
\end{tabular}


Table 4. Comparison of linear regression by and MK test

\begin{tabular}{|c|c|c|c|c|}
\hline \multirow{2}{*}{ Range } & \multicolumn{2}{|c|}{ Linear regression } & \multicolumn{2}{|c|}{ Mann-Kendall test } \\
\hline & slope & $\mathbf{p}$ & Slope & $\mathbf{P}$ \\
\hline TGRA & -4.0835 & 0.000 & -3.51222 & 0.000 \\
\hline Zigui & -5.9291 & 0.003 & -6.47931 & 0.000 \\
\hline Fengjie & -5.8943 & 0.004 & -7.54988 & 0.001 \\
\hline Badong & -5.6037 & 0.004 & -3.90759 & 0.001 \\
\hline Xingshan & -4.9178 & 0.009 & -5.32145 & 0.001 \\
\hline Jiangjin & -4.3442 & 0.000 & -5.27061 & 0.000 \\
\hline Fangxian & -4.3374 & 0.256 & -4.88133 & 0.011 \\
\hline Changshou & -3.9764 & 0.113 & -4.90930 & 0.079 \\
\hline Shapingba & -3.3637 & 0.107 & -3.66487 & 0.028 \\
\hline Qijiang & -3.3548 & 0.000 & 2.27005 & 0.340 \\
\hline Nanzhang & -3.3094 & 0.109 & -4.31300 & 0.123 \\
\hline Dazu & -3.1900 & 0.007 & -2.69893 & 0.186 \\
\hline Wufeng & -3.166 & 0.068 & -3.14782 & 0.006 \\
\hline Xishui & -2.7756 & 0.296 & -3.76804 & 0.168 \\
\hline Hechuan & -2.6239 & 0.079 & -2.43572 & 0.753 \\
\hline Liangping & -1.9479 & 0.236 & -2.26090 & 0.320 \\
\hline Jingzhou & -1.0154 & 0.272 & -0.15550 & 0.359 \\
\hline Lichuan & -1.0022 & 0.239 & -1.12735 & 0.175 \\
\hline Daxian & -0.57336 & 0.277 & 2.99586 & 0.505 \\
\hline Wanzhou & -0.43804 & 0.536 & 1.78721 & 0.631 \\
\hline Jianshi & -0.28092 & 0.662 & -0.11092 & 0.688 \\
\hline Fengdu & 0.39448 & 0.282 & 1.42686 & 0.735 \\
\hline Zhenping & 0.67457 & 0.631 & 0.69036 & 0.487 \\
\hline Yichang & 1.2569 & 0.319 & 2.06214 & 0.393 \\
\hline Tongzi & 1.4852 & 0.462 & 2.10545 & 0.120 \\
\hline Qianjiang & 1.6593 & 0.743 & 2.27005 & 0.340 \\
\hline Wanyuan & 2.3927 & 0.005 & 4.55452 & 0.000 \\
\hline Enshi & 2.508 & 0.035 & 2.77627 & 0.013 \\
\hline
\end{tabular}

Fig. 7 presents the spatial distribution of the climate changing rate in study area. The climate changing rate of northern bank is $-18.1 \mathrm{~mm} / \mathrm{decade}$, which is lower than the rate of southern bank $(-20.2 \mathrm{~mm} /$ decade $)$. And the rate inside the TGRA is $-32.8 \mathrm{~mm} /$ decade, which is higher than the rate of its surroundings $(-11.1 \mathrm{~mm} / \mathrm{decade})$. Ep falls by a large margin near the $111^{\circ} 0^{\prime} 0^{\prime \prime} \mathrm{E}$, which is just at the junction zone of the valley and the peak. Almost all of the seven increasing trend stations are located in the mountainous area. However, by investigating interconnections between the altitude, longitude, and latitude (Fig. 8), no significant relationship between them was found. 


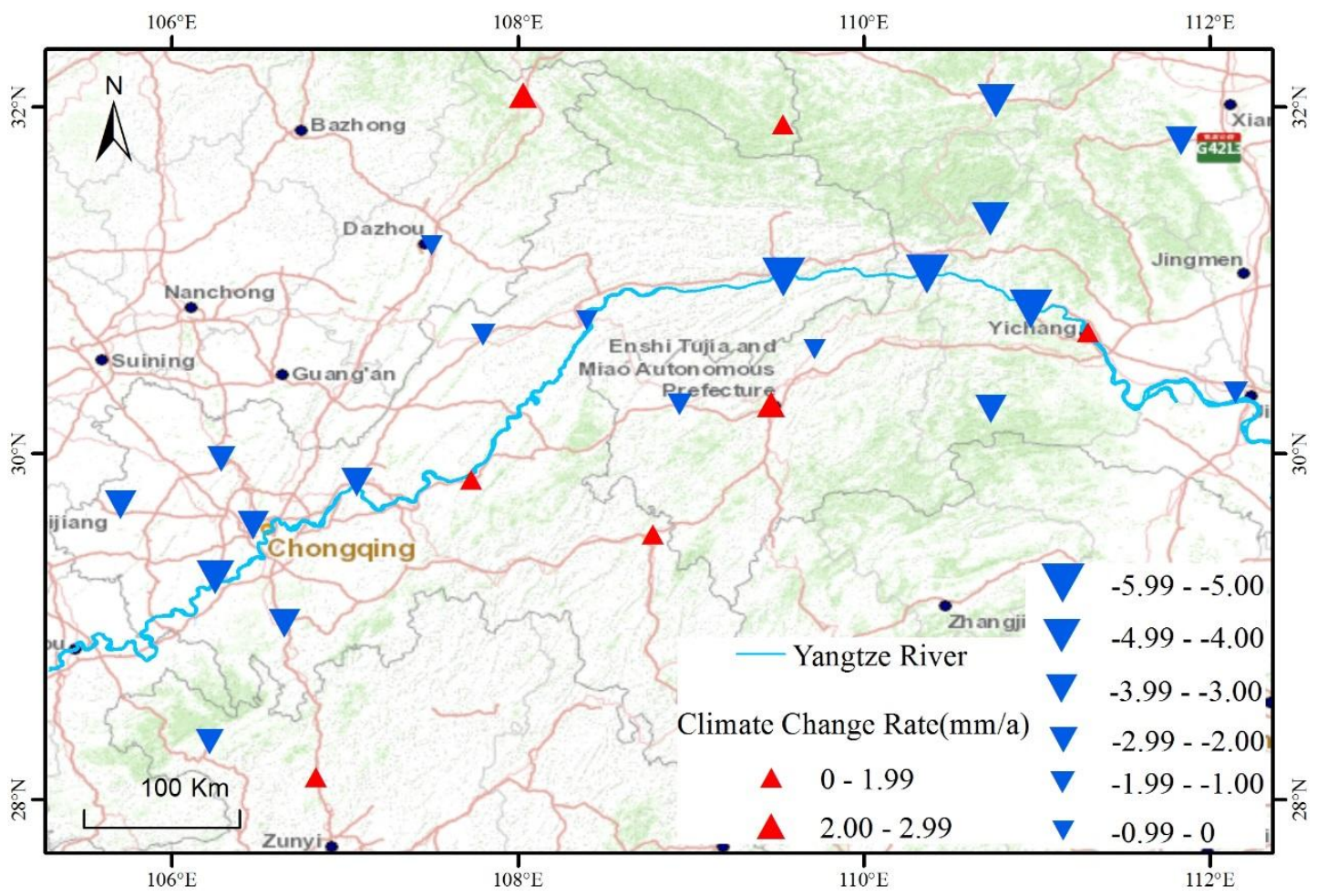

Figure 7. Spatial distribution of climate changing rate in study area during 1932-2013

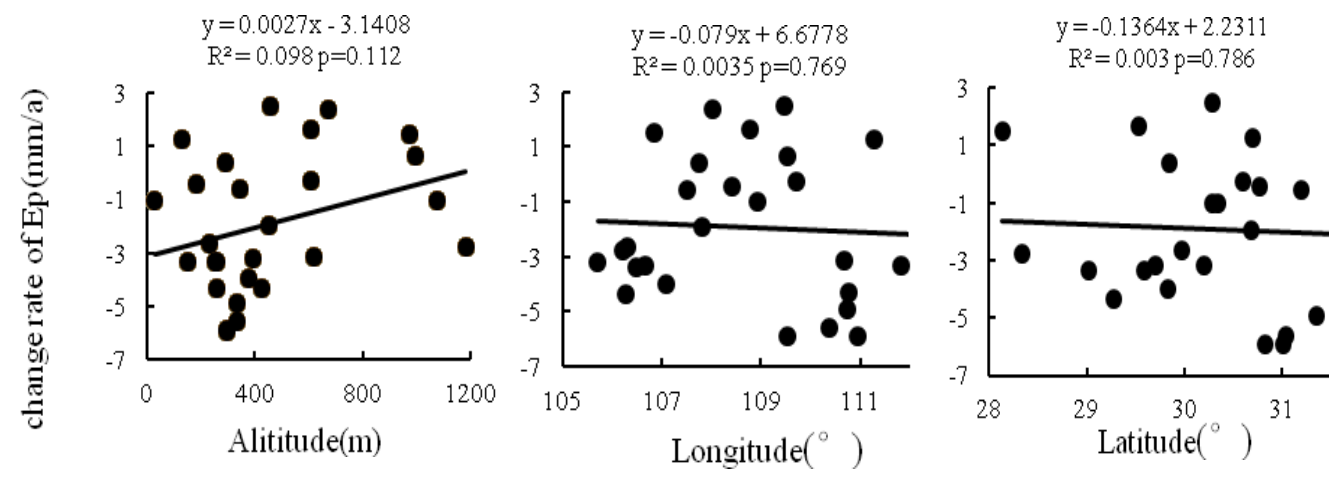

Figure 8. Relationship between altitude, longitude, latitude and climate change rate of pan evaporation

Although annual pan evaporation for most stations during 1952-2013 was identified to be a decreasing trend, it was not in a continued decline during five sub periods (1960-1969, 1970-1979, 1980-1989, 1990-1999, 2000-2009). In first two periods, the pan evaporation has no significant increasing trend. But the trend shows no significance in the next two periods. At the last period, the pan evaporation significantly drops at the rate of $-20.98 \mathrm{~mm} / \mathrm{a}$ (Table 5). 


\section{Meteorological relations}

In study area, the air temperature (TEM) increased by $0.067 /$ decade during the period of 1952-2013. The pan evaporation are expected to increase by influence of the warmer air. However, the evaporation paradox occurred in the TGRA and its surroundings, leading to unexpected results. Meanwhile, wind speed (WIN), sunshine duration (SSD) and relative humidity (RHU) also declined at rate of $-0.03 \mathrm{~m} / \mathrm{s} /$ decade, $-30.8 \mathrm{~h} / \mathrm{a} /$ decade, $-0.14 \% /$ decade (Fig. 9), respectively. Because the evaporation surface is free water surface, the pan evaporation rate is not affected by the water supply. Since the precipitation just has an indirect impact through the relative humidity, there is no separate study on the impact of precipitation. By multiple influence of other elements together, pan evaporation showed a significant decreasing trend. Comparing time series of average annual pan evaporation with the meteorological factors mentioned above, the results show that pan evaporation has the strongest positive correlation with SSD, and strongest negative correlation with relative humidity (Table 6). At one hand, the less SSD provides the less power of evaporation, at the other hand, the lower RHU means the huge air capacity to contain water vapor.

Table 5. The climate change rate of pan evaporation in each era

\begin{tabular}{|c|c|c|c|}
\hline Era & Annual $\mathbf{E}_{\mathrm{p}}(\mathbf{m m})$ & $\begin{array}{c}\text { Slope } \\
(\mathbf{m m} / \mathbf{a})\end{array}$ & $\mathbf{p}$ \\
\hline 1960-1969 & 1308.88 & 8.60 & 0.403 \\
\hline 1970-1979 & 1419.49 & 11.56 & 0.164 \\
\hline 1980-1989 & 1135.95 & -1.09 & 0.889 \\
\hline 1990-1999 & 1205.73 & -4.47 & 0.527 \\
\hline 2000-2009 & 1101.92 & -20.98 & 0.050 \\
\hline
\end{tabular}
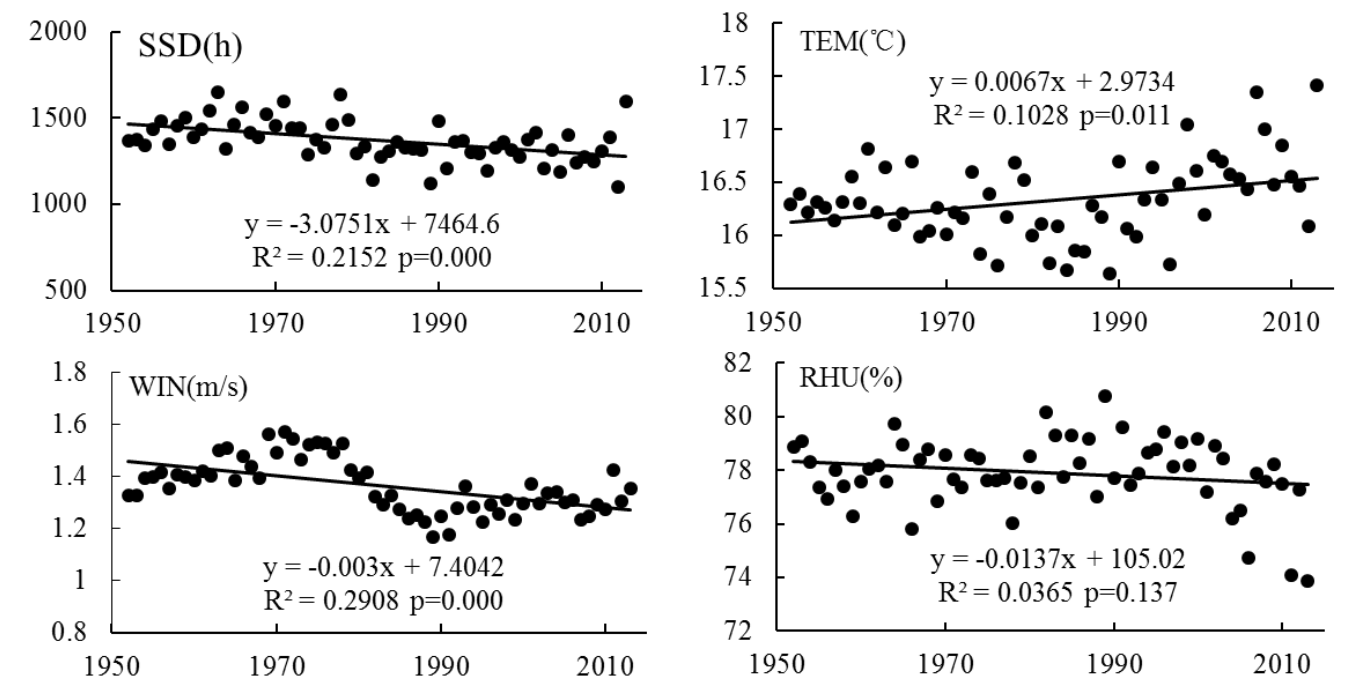

Figure 9. Mean annual SSD, TEM, WIN, RHU by linear regression in study area during 1952-2013 
In order to explain the decreasing trend of Ep with the other elements by multiple correlation analysis, the multivariable linear regression model was applied to test quantitative relation. Standard regression equation was as below:

$$
\mathrm{E}_{\mathrm{p}}=0.467 \mathrm{ssd}+0.178 \text { tem }+0.132 \text { win }-0.299 \mathrm{rhu}+9.296 \mathrm{E}-16 \quad(\mathrm{p}=0.000)
$$

The models performed well in representing both the observed trends and Ep values in most cases, and passed the F-test at a significant level of $99 \%$.

It was found that Ep was highly correlated with SSD, with a linear regression coefficient of 0.467 . In TGRA, the SSD declined at the speed of about $-30.75 \mathrm{~h} /$ decade. Its decreasing means the downward trend of radiation. It has a close connection with the air pollution. Industrial production and automobile exhaust discharged a large number of nitrogen oxides, organic compounds and dusts. Lots of aerosol reflected and absorbed radiation from the sun and resulted in less solar radiation reaching the earth surface. It has reduced the energy supply for liquid water transforming to gaseous water. Furthermore, water molecules cannot escape the attraction between molecules.

Wind speed also declined in study area over this period. Decreased Ep accompanied by decreasing wind speed has also been reported in the Tibetan Plateau, the Loess Plateau. In those regions, the moisture condition of the underlying surface has little change. But, the decreased wind speed is expected to make near-surface air less movement, more saturated and, as such, weaken evaporation capacity. In this study area, the water supply is adequate. Because of the hilly terrain, the wind is not strong enough to blow quickly the water vapor off the evaporating surface. Thus, the wind speed becomes the limiting factor. Some authors have argued that changes in atmospheric circulation have resulted in a decrease in wind speed, possibly related to global warming trends.

Table 6. Pearson correlation coefficient between pan evaporation and TEM, WIN, SSD, RHU

\begin{tabular}{ccc}
\hline Meteorological Element & Pearson correlation & p \\
\hline TEM & 0.496 & 0.000 \\
WIN & 0.493 & 0.000 \\
SSD & 0.751 & 0.000 \\
RHU & -0.648 & 0.000 \\
\hline
\end{tabular}

According to the multivariable linear regression, $\mathrm{E}_{\mathrm{p}}$ has negative correlation with RHU. The less RHU, the dryer air, the more capacity for the water vapor, which accelerate the evaporation. $E_{p}$ trend is, thus, the result of a variety of factors. Although change of RHU just slowed down the trend of decline in the study area, it cannot fundamentally reverse the decreasing trend. 


\section{Conclusion and future prospects}

As one of the regular observations in hydrology and meteorology, the pan-evaporation is an important reference index for evaluating water resources in studying hydrology and climatology. Furthermore, it has a much greater significance on the water use, heat balance, crop growth etc. Therefore, it is highly valuable for further study in regulation and causes of $E_{p}$ change. By analyzing the $E_{p}$ in TGRA and its surroundings during 1952-2013, our main conclusions are as follows:

- The analysis results show that the spatial distribution of the annual pan evaporation has an east -west gradient, which is coincident with SSD and WIN, but opposite to the TEM, RHU.

- Our analysis proves that the "evaporation paradox" also occurred in the study area. The annual pan evaporation significantly decline at the rate of -40.8 $\mathrm{mm} /$ decade. It shows an increasing trend in $60 \mathrm{~s}$ and a decreasing trend in $80 \mathrm{~s}$ and 90s. However, both trends were at insignificant level. In 2000's the annual pan evaporation shows a decreasing trend at a statistically significant level at rate of $20.98 \mathrm{~mm} / \mathrm{a}$.

- The results supports the interpretation that the widespread decline of pan evaporation is mainly caused by decrease of solar radiation.

Finally, several points that may enhance the study on future were discussed below. In this study, data from 27 observation stations were applied. To improve accuracy of the study's outcome, data from more stations will be needed; the pan evaporation influenced by water and energy conditions is the result by joint effects of not just meteorological, but also geographical factors. Further study may be required on future in studying the geographical effect of pan evaporation. Based on the current analysis, it can't be explained that the direct impact of the Three Gorges Reservoir on pan evaporation. More data and work are needed.

Acknowledgements. The work was supported by West Light Foundation of the Chinese Academy of Sciences, National Natural Science Foundation of China (41401051), STS project (KFJ-SW-STS-180) Chongqing Science and Technology project (cstc2015jcyjA00007), Fuling Science and Technology project(2016ABB1040), Opening Fund of Key Laboratory of Poyang Lake Wetland and Watershed Research, Ministry of Education (WE2016002,ZK2015001). We thank the National Meteorological Information Center, China Meteorological Administration for providing the long-term data records. Many thanks go to the anonymous reviewers for the comments on the manuscript.

\section{REFERENCES}

[1] Almazroui, M., Islam, M. N., Dambul, R., Jones, P. D. (2014): Trends of temperature extremes in Saudi Arabia. - International Journal of Climatology 34(3): 808-826.

[2] Brutsaert, W. (2016): Global land surface evaporation trend during the past half century: Corroboration by Clausius-Clapeyron scaling. - Advances in Water Resources, in press.

[3] Chattopadhyay, N., Hulme, M. (1997): Evaporation and potential evapotranspiration in India under conditions of recent and future climate change. - Agricultural and Forest 
Meteorology 87(1): 55-73.

[4] Croitoru, A.-E., Piticar, A., Dragotă, C. S., Burada, D. C. (2013): Recent changes in reference evapotranspiration in Romania. - Global and Planetary Change 111: 127-136.

[5] Fu, G., Charles, S. P., Yu, J. (2009): A critical overview of pan evaporation trends over the last 50 years. - Climatic Change 97(1): 193-214.

[6] Fu, B.-J., Wu, B.-F., Lü, Y.-H., Xu, Z.-H., Cao, J.-H., Niu, D., Yang, G.-S., Zhou, Y.-M. (2010): Three Gorges Project: efforts and challenges for the environment. - Progress in Physical Geography 34(6): 741-754.

[7] Ge, Q., Wang, H., Rutishauser, T., Dai, J. (2015): Phenological response to climate change in China: a meta-analysis. - Global Change Biology 21(1): 265-274.

[8] Hobbins, M. T., Ramírez, J. A., Brown, T. C. (2004): Trends in pan evaporation and actual evapotranspiration across the conterminous U.S.: Paradoxical or complementary? Geophysical Research Letters 31(13): 211-224.

[9] Hoffman, M. T., Cramer, M. D., Gillson, L., Wallace, M. (2011): Pan evaporation and wind run decline in the Cape Floristic Region of South Africa (1974-2005): implications for vegetation responses to climate change. - Climatic Change 109(3): 437-452.

[10] IPCC. (2013): Climate Change 2013: The Physical Science Basis. Contribution of Working Group I to the Fifth Assessment Report of the Intergovernmental Panel on Climate Change [Stocker, T.F., D. Qin, G.-K. Plattner, M. Tignor, S.K. Allen, J. Boschung, A. Nauels, Y. Xia, V. Bex and P.M. Midgley (eds.)]. - Cambridge University Press, Cambridge, United Kingdom and New York, NY, USA, 1535 pp, doi:10.1017/CBO9781107415324.

[11] Ji, X.-J., Wang, J.-J., Gu, W.-L., et al. (2012): Trends in Annual and Seasonal Pan Evaporation in the Lower Yellow River Basin from 1961 to 2010. - Advances in Climate Change Research 3(4): 195-204. doi: 10.3724/SP.J.1248.2012.00195.

[12] Jones, G. S., Lockwood, M., Stott, P. A. (2012): What influence will future solar activity changes over the 21 st century have on projected global near-surface temperature changes? - Journal of Geophysical Research-Atmospheres 117.

[13] Lawrimore, J. H., Peterson, T. C. (2000): Pan Evaporation Trends in Dry and Humid Regions of the United States. - Journal of Hydrometeorology 1(6): 543-546.

[14] Litchfield, J. T., Wilcoxon, F. (1955): Rank Correlation Method. - Analytical Chemistry 27(2): 299-300.

[15] Liu, B., Xu, M., Henderson, M., Gong, W. (2004): A spatial analysis of pan evaporation trends in China, 1955-2000. - Journal of Geophysical Research: Atmospheres 109(D15): 56-78.

[16] Liu, X., Luo, Y., Zhang, D., Zhang, M., Liu, C. (2011a): Recent changes in pan-evaporation dynamics in China. - Geophysical Research Letters 38(13): 142-154.

[17] Liu, X., Zheng, H., Zhang, M., Liu, C. (2011b): Identification of dominant climate factor for pan evaporation trend in the Tibetan Plateau. - Journal of Geographical Sciences 21(4): 594-608.

[18] Modak, S. K., Ortíz, L., Peña, I., Sudarsky, D. (2015): Black hole evaporation: information loss but no paradox. - General Relativity and Gravitation 47(10): 120.

[19] Moonen, A. C., Ercoli, L., Mariotti, M., Masoni, A. (2002): Climate change in Italy indicated by agrometeorological indices over 122 years. - Agricultural and Forest Meteorology 111(1): 13-27.

[20] Ozdogan, M., Salvucci, G. D. (2004): Irrigation-induced changes in potential evapotranspiration in southeastern Turkey: Test and application of Bouchet's complementary hypothesis. - Water Resources Research 40(4): W04301.

[21] Peterson, T. C., Golubev, V. S., Groisman, P. Y. (1995): Evaporation losing itsstrength. Nature 377(6551): 687-688.

[22] Rayner, D. P. (2007): Wind Run Changes: The Dominant Factor Affecting Pan Evaporation Trends in Australia. - Journal of Climate 20(14): 3379-3394. 
[23] Roderick, M. L., Farquhar, G. D. (2004): Changes in Australian pan evaporation from 1970 to 2002. - International Journal of Climatology 24(9): 1077-1090.

[24] Roderick, M. L., Farquhar, G. D. (2005): Changes in New Zealand pan evaporation since the 1970s. - International Journal of Climatology 25(15): 2031-2039.

[25] Rowshon, M. K., Amin, M. S. M., Mojid, M. A., Yaji, M. (2014): Estimated evapotranspiration of rice based on pan evaporation as a surrogate to lysimeter measurement. - Paddy and Water Environment 12(1): 35-41.

[26] Schlesinger, W. H., Jasechko, S. (2014): Transpiration in the global water cycle. Agricultural and Forest Meteorology 189-190(1): 115-117.

[27] Shenbin, C., Yunfeng, L., Thomas, A. (2006): Climatic change on the Tibetan Plateau: Potential Evapotranspiration Trends from 1961-2000. - Climatic Change 76(3): 291-319.

[28] da Silva, V. d. P. R. (2004): On climate variability in Northeast of Brazil. - Journal of Arid Environments 58(4): 575-596.

[29] Strachan, I. B., Tremblay, A., Pelletier, L., Tardif, S., Turpin, C., Nugent, K. A. (2016): Does the creation of a boreal hydroelectric reservoir result in a net change in evaporation? - Journal of Hydrology 540: 886-899.

[30] Tabari, H., Marofi, S. (2010): Changes of Pan Evaporation in the West of Iran. - Water Resources Management 25(1): 97-111.

[31] Tang, Q., Bao, Y., He, X., Fu, B., Collins, A. L., Zhang, X. (2016): Flow regulation manipulates contemporary seasonal sedimentary dynamics in the reservoir fluctuation zone of the Three Gorges Reservoir, China. - Science of The Total Environment 548-549: 410-420.

[32] Tebakari, T., Yoshitani, J., Suvanpimol, C. (2005): Time-Space Trend Analysis in Pan Evaporation over Kingdom of Thailand. - Journal of Hydrologic Engineering 10(3): 205-215.

[33] Trenberth, K. E., Asrar, G. R. (2014): Challenges and Opportunities in Water Cycle Research: WCRP Contributions. - Surveys in Geophysics 35(3): 515-532.

[34] Valipour, M. (2014): Use of average data of 181 synoptic stations for estimation of reference crop evapotranspiration by temperature-based methods. - Water Resources Management 28(12): 4237-4255.

[35] Wang, Y., Liu, B., Su, B., Zhai, J., Gemmer, M. (2011): Trends of Calculated and Simulated Actual Evaporation in the Yangtze River Basin. - Journal of Climate 24(16): 4494-4507.

[36] Wu, J., Huang, J., Han, X., Xie, Z., Gao, X. (2003): Three-Gorges Dam--Experiment in Habitat Fragmentation? - Science 300(5623): 1239-1240.

[37] Wu, J., Huang, J., Han, X., Gao, X., He, F., Jiang, M., Jiang, Z., Primack, R. B., Shen, Z. (2004): The three gorges dam: an ecological perspective. - Frontiers in Ecology and the Environment 2(5): 241-248.

[38] Xia, F., Liu, X., Xu, J., Wang, Z., Huang, J., Brookes, P. C. (2015): Trends in the daily and extreme temperatures in the Qiantang River basin, China. - International Journal of Climatology 35(1): 57-68.

[39] Xie, H., Zhu, X., Yuan, D.-Y. (2015): Pan evaporation modelling and changing attribution analysis on the Tibetan Plateau (1970-2012). - Hydrological Processes 29(9): 2164-2177.

[40] Yang, Z., Wang, H., Saito, Y., Milliman, J. D., Xu, K., Qiao, S., Shi, G. (2006): Dam impacts on the Changiiang (Yangtze) River sediment discharge to the sea: The past 55 years and after the Three Gorges Dam. - Water Resources Research 42(4): 501-517.

[41] Yang, K., Wu, H., Qin, J., Lin, C., Tang, W., Chen, Y. (2014): Recent climate changes over the Tibetan Plateau and their impacts on energy and water cycle: A review. - Global and Planetary Change 112: 79-91.

[42] Zuo, H., Chen, B., Wang, S., Guo, Y., Zuo, B., Wu, L., Gao, X. (2016): Observational study on complementary relationship between pan evaporation and actual evapotranspiration and its variation with pan type. - Agricultural and Forest Meteorology 222: 1-9. 